Research Strategies, Vol. 17, No. 2-3, 2000, pp.207-214.

ISSN: 0734-3310

doi: 10.1016/S0734-3310(00)00040-9

http://www.elsevier.com/wps/find/homepage.cws_home

http://www.sciencedirect.com/science/journal/07343310

http://www.sciencedirect.com/science/article/B6W60-430XPV2-K/2/a801522f9d7f1978ae931f08f2b215b5

(c) 2001 Elsevier Science Inc. All rights reserved.

\title{
Ohio State University Libraries' net.TUTOR project
}

\author{
Nancy O'Hanlon \\ Ohio State University Libraries, $\mathrm{OH}$
}

\begin{abstract}
The Showcase of Ideas at the 1997 ACRL President's Program provided a valuable opportunity to share plans and a sample lesson from the Ohio State University Libraries' net.TUTOR program. At that time, net.TUTOR was in its initial development phase. This article, written from the perspective of almost 2 full years of managing and expanding this program, will discuss the early vision for net.TUTOR, how the program actually developed, how it has been used during the 2 years that followed, and future plans for the program.
\end{abstract}

\section{Introduction}

The Ohio State University Libraries' net.TUTOR program «http://gateway.lib.ohiostate.edu/tutor> offers Web-based, interactive tutorials on basic tools and techniques for becoming an effective Internet researcher. An Academic Enrichment Grant from Ohio State University to the University Libraries in 1996 initiated the project and provided funds for a new position to develop and maintain the tutorial program. Nancy O'Hanlon began as project librarian in November 1996. Following more than 6 months of needs assessment and prototyping, 10 tutorials were completed during the summer and made publicly available in September 1997. This article will discuss the early vision for net.TUTOR, how the program has been developed and utilized, and future plans for the program.

\section{Goals and structure}

The name chosen for this instructional program, net.TUTOR, includes an acronym that represents the overarching project goal: Teaching $U$ seful Techniques for $O$ nline $R$ esearch. The following broad goals guided development of net.TUTOR:

- To use a conceptual framework for instruction, relating Internet research concepts to general information-seeking behavior in other situations.

- To employ active-learning principles, providing practice opportunities and constructive feedback whenever appropriate.

- To allow self-assessment, flexible selection of tasks and channels for user comments.

- To use Web technology appropriately and effectively, insuring that essential information is available to all users. 
By June 1997, 10 tutorial topics had been identified through feedback from public service colleagues and from the project Advisory Council, composed of teaching faculty, librarians, members of the computing center staff and students. These topics were arranged in two groups - Beginner Lessons and Advanced Lessons. Each group would include a tutorial on browsers, communication tools, types of information available, searching and research techniques.

All tutorials would include a "Classroom" section, providing a mini-lecture with illustrations, examples and short practice opportunities, as well as a "Quiz," with feedback on answers selected. "Webliographies," or lists of links to additional sources of information, and "Quick Guides," concise summaries of important points, would also be available for a number of tutorials. Feedback from several classes that had used a model lesson on evaluation of Web sites during winter and spring 1997 was quite helpful in refining the interface shown in Fig. 1.

The sample screen shown in Fig. 1 illustrates the design approach used throughout version 1.0 of net.TUTOR. A navigation frame is present at the top of each screen. Information frames use a concise two-column format, with instructional text on the left and examples or practice opportunities on the right. Most examples (screen pictures) are available as links rather than as images within the page itself, allowing users to select those that they wish to view. This technique also results in faster download times for users connecting via modem.

\section{Technical issues}

Technical issues involved in the initial implementation of net.TUTOR and identified in a handout prepared for the Showcase of Ideas at the 1997 program included:

- Planned use of commercial course management software to manage logins and authentication, maintain the user's place, provide feedback on progress, track patterns of behavior within the site and transmit grades.

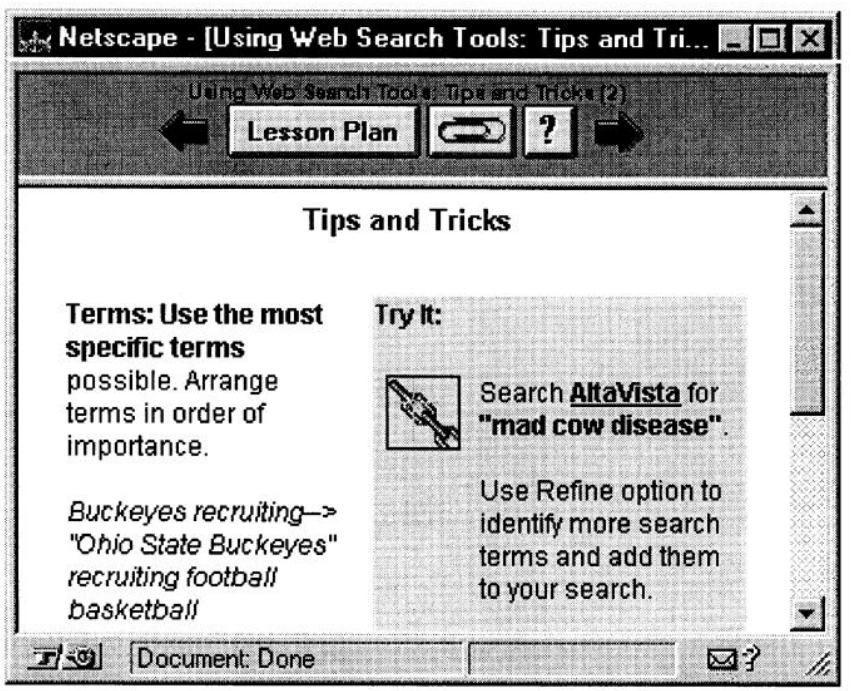

Fig. 1. Sample tutorial "Classroom" screen, version 1.0. 
- Use of Javascript to open new windows selectively for links to external sites.

- Development constraints related to a high volume of potential users who were expected to use a very early version of the Netscape browser being distributed by the university.

- Later augmentation with optional Shockwave animations.

Version 1.0 of net.TUTOR does use commercial software from IBTauthor (now called Docent). Research studies of user behavior based on the history logs provided by this software have been valuable in program evaluation and development. Data from these studies were presented at a recent ACRL conference (O'Hanlon \& Roecker, 1999) and will also be reported in a forthcoming article in the Journal of Interactive Learning Research (O'Hanlon, 1999).

Although we anticipated that users might "wander away" from the tutorials by following external links, our solution of using new browser windows to display external links thoroughly confused many of the users of the prototype lessons. This potential problem was addressed more successfully by the course management software, which uses optional frames to control lesson navigation. When users select a link to an external site, these new pages are displayed within the navigational frame provided by IBTauthor.

We also expected, in early stages of development, to augment net.TUTOR with Shockwave animations at a later date. As Web use became more ubiquitous, however, it was apparent that any reliance on plug-ins would hinder use of the program. The simplest approach to presenting content, one that works across the majority of browsers and does not depend upon users having the newest versions fully loaded with plug-ins, was ultimately chosen.

\section{Program implementation and use}

After version 1.0 of net.TUTOR was announced in September 1997, a number of faculty members expressed interest in adding it as a component of their courses. During the first full year of availability, 30 classes at Ohio State, ranging from the large enrollment University Survey class for freshmen and transfer students (UVC 100) to graduate classes in education and law, had a net.TUTOR assignment of some type. During the second year, 39 courses, spanning a wide range of disciplines, used the program. Instructors view the program as a way to guarantee that students have a foundation of skills upon which they can build more complex Internetrelated assignments.

Approximately 5000 registered users have completed 12,300 tutorials since the inception of the program. Studies of user history logs maintained by the courseware show that the average user spends about 16 minutes per tutorial. Using this benchmark, we can estimate that almost 3300 hours of individual instruction have been provided by this version of net.TUTOR to date.

Basic lessons on Web browsing, using email, and database and Web searching have been most the popular tutorials throughout the 2 years that the program has been available. During 1998-1999, use of the tutorial on evaluation of Web sites increased significantly. This interest was spurred by two factors: more faculty members required the use of this tutorial and the tutorial menu was reconfigured to give it more prominence.

Review of evaluative data from fall quarter 1997 revealed that dividing tutorials into two groups, Beginner and Advanced, was not meaningful to users. The tutorials were subsequently reorganized into topical groups without "level" designators, as shown in Fig. 2. "Basics" includes the introductory browsing and email tutorials. "Using Net Tools" provides more advanced information on browsers, mailing lists, and newsgroups. "Searching" includes beginning and 


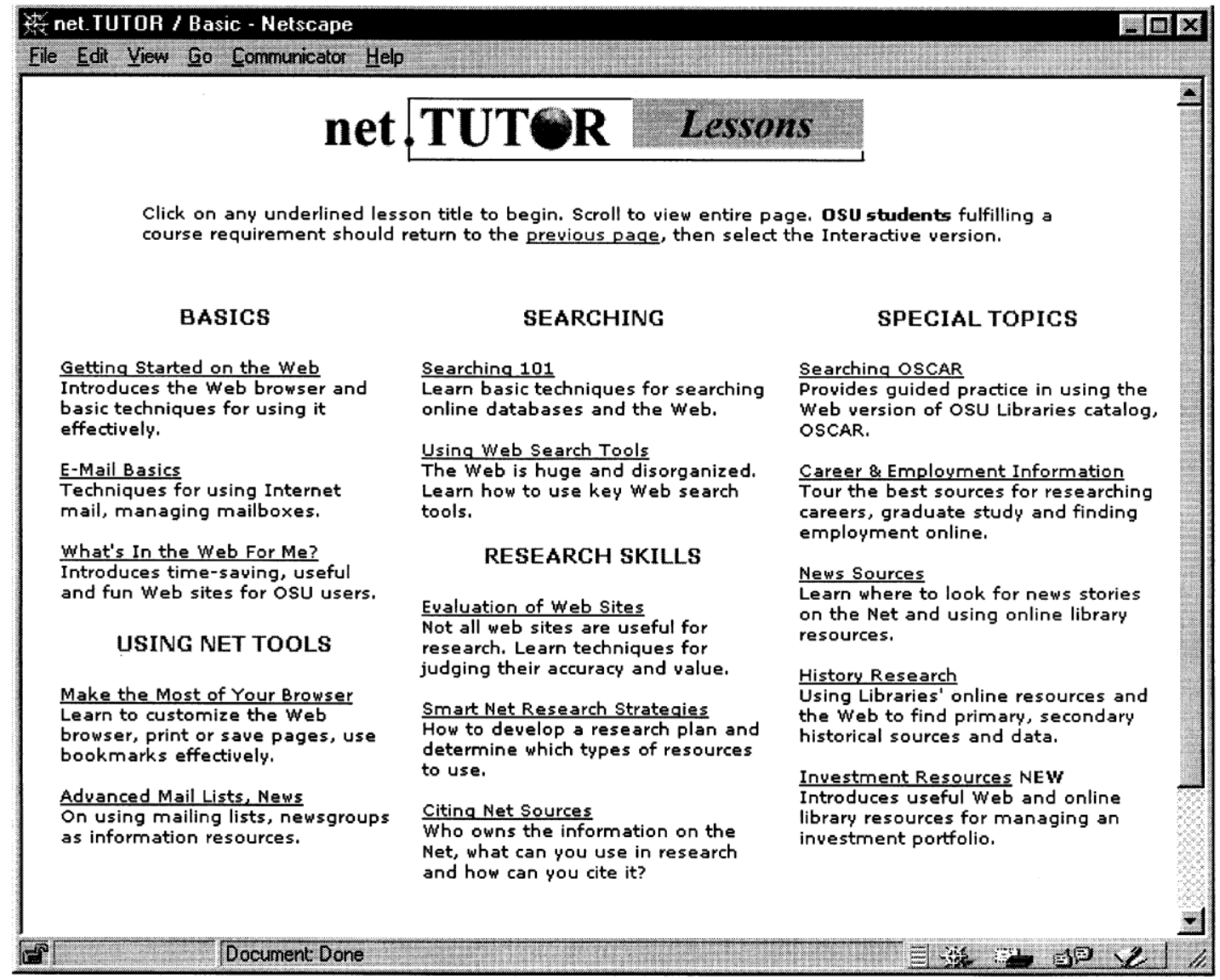

Fig. 2. Tutorial menu screen, version 1.0.

more advanced search tutorials. "Research Skills" includes tutorials on evaluation, research strategy and citing sources. Finally, "Special Topics," a fifth category added later in the year, includes new tutorials on OSCAR (the OSU Libraries catalog), News Sources, Career and Employment Information, History Research and Investment Resources. These tutorials were developed in partnership with interested faculty or library colleagues.

User surveys linked to each tutorial have been a major source of evaluative data about the program. From 1997 to the present, more than 9000 surveys have been returned. Using a Likert scale from 1 (lowest) to 5 (highest), the program's overall satisfaction ratings have remained consistently high. Forty-six percent of respondents to this question rated the tutorials 4 or 5 . About $20 \%$ of users dislike the program, giving it a 1 or 2 rating, although this percentage varies considerably when filtered by whether the user was required to use the program for a course or chose it freely as an educational aid.

About $60 \%$ of respondents indicate that they utilize some of the practice opportunities available within lessons, while $12 \%$ state that they complete many activities. A variety of charts based on this survey data are available on the net.TUTOR Web site. 


\section{Solving problems}

Success sometimes breeds problems. In the case of net.TUTOR, the most significant problems that emerged from evaluations were slow response time and quiz errors during especially busy periods. Both problems are directly related to use of course management software, which relies on a relational database to build pages on-the-fly and store user data of various types.

As a short-term solution, an "open" version of net.TUTOR was developed in winter 1998. During 1997-1998, about $22 \%$ of users were from outside the university. It was hoped that this version, which does not utilize the courseware or require registration, would be attractive to those users, who often were not interested in the quiz capabilities of the other, interactive version managed by IBTauthor. Another facet of solving this problem involved upgrading both the server on which the program was running and the database software used by the course management program. These upgrades have been phased in over the past year, resulting in improved performance and fewer errors.

\section{Version 2.0 plans}

Version 2.0 of net.TUTOR, which was made publicly available in fall 1999, does not employ course management software. Instead, users connect directly to open versions of each tutorial, without any pre-registration. Although some user data will be lost as a result of this change, we believe that it will alleviate most problems with quiz errors and dramatically improve response time.

The testing function formerly provided by the course management software has moved to Course Sorcerer, a new application developed by the computing staff at Ohio State University for use by university faculty. This secure online testing and assignment delivery system is used to provide tests on the content of net.TUTOR tutorials for those students who are enrolled in courses that require use of the program. An added benefit of Course Sorcerer is that students are authorized using their existing OSU Internet username and password, the same one that is used to gain access to email accounts, grades, online registration and other secure services at the university. As was the case with version 1.0, reports of student test grades are provided to instructors who have assigned use of net.TUTOR for their course.

Since graded tests are not available to users outside of OSU courses with net.TUTOR assignments, others who wish to assess their progress and reinforce learning of important concepts may use new "Quick Quiz" questions embedded throughout each tutorial. Quick Quiz questions, as shown in Fig. 3, use Javascript to provide immediate feedback, but no scores are retained by the system.

The design approach for version 2.0 has changed as well. Version 1.0 used a horizontal navigation frame at the top of the browser window. The new version does not employ frames. All screens use a simple, one-column format, and, based on frequent suggestions from users, each screen contains much more text than was included in the previous version. Most browser users now understand the need to scroll in order to read all of the text within a browser window. Jakob Nielsen (1997) notes that "in more recent studies, we have seen that most users have started scrolling when they visit a long home page or a long navigation screen. This change in behavior is probably due to users getting more experience with scrolling Web pages". Nielsen also suggests that users like to print and retain Web pages. The new design approach facilitates 
easier printing of tutorial content and provides better accessibility for those using screen reader software.

In January 1999, the Office of Academic Affairs at Ohio State University convened a new Committee on Student Computing Competencies and charged it with defining a set of computing skills that will be expected of undergraduate students at the university. The Committee has identified computing skills broadly in four categories:

- Communication;

- Research and discovery;

- Product creation; and

- Information use/management.

As a result of the Committee's work, net.TUTOR will be widely promoted by the university as a primary means for acquiring many of the recommended competencies and as a jumping off point for finding the most useful learning resources. As Fig. 4 illustrates, the new net.TUTOR home page will link to a description of the competencies and will also include a tutorial database that can be used to identify the best online learning resources for particular needs.

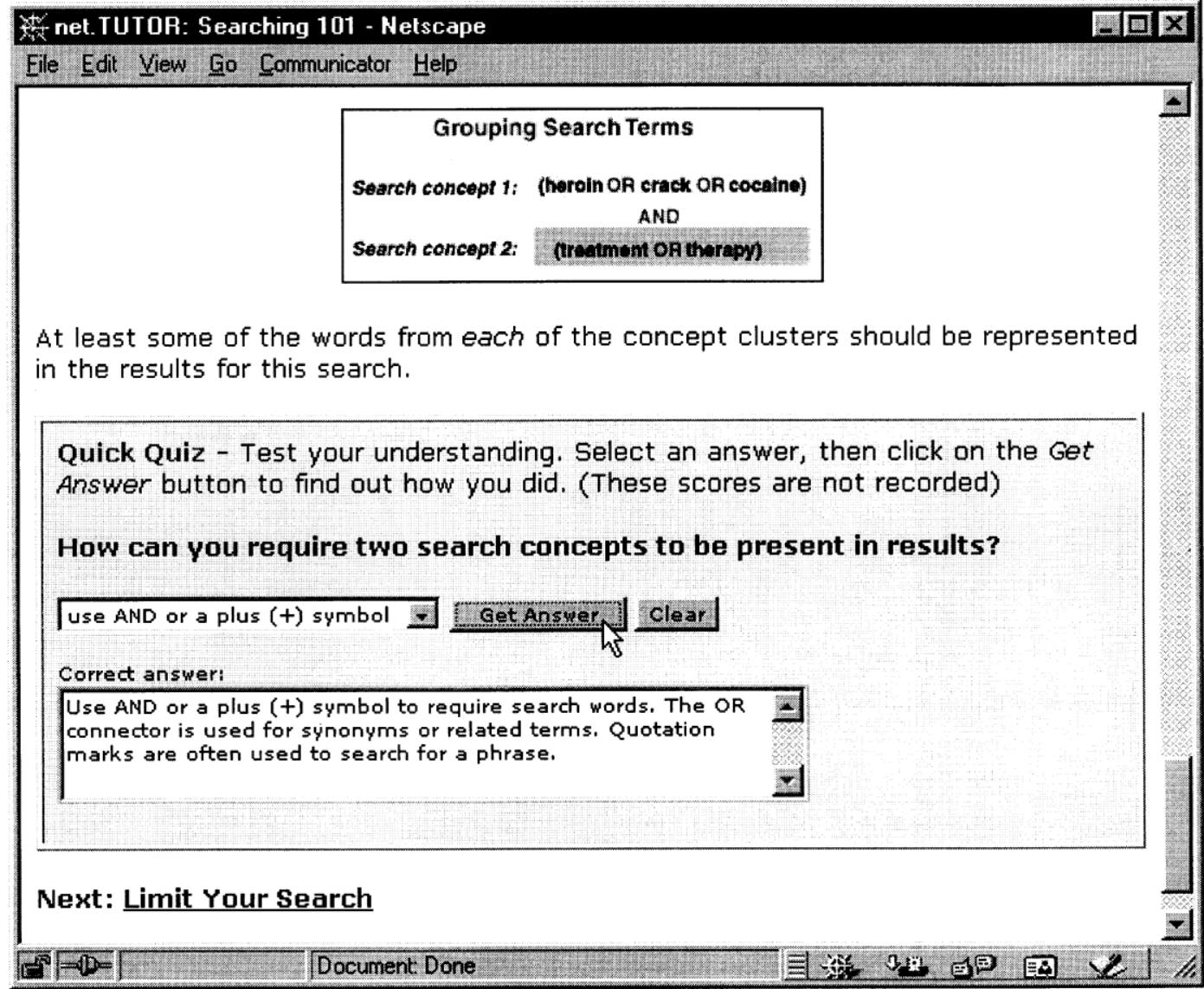

Fig. 3. Tutorial screen, version 2.0, with "Quick Quiz" question. 
Finally, net.TUTOR 2.0 will serve as the online textbook for a new, one-credit distance course, UVC 120, Internet Tools and Research Techniques. This course was developed by the author in partnership with the University College (UVC), the unit into which most new students are enrolled at Ohio State, and the Office of Technology Enhanced Learning and Research, a unit that reports to the Chief Information Officer and provides support for distance learning activities at Ohio State University.

Five hundred students who entered the university in fall quarter enrolled for the first 4week session conducted during August 1999. These students used the tutorials and took tests associated with them, chose from other optional readings, and completed six additional online assignments. This course will also be offered during the regular autumn, winter, and spring quarters as well, with an enrollment limit of 250 students for each session. More information about this credit course is available at (http://gateway.lib.ohio-state.edu/tutor/course).

During the past two years, net.TUTOR has developed into a mature instructional program that serves independent learners at Ohio State and around the world, is used as a module of courses taught by a variety of OSU faculty and is the foundation of a distance course managed by the libraries. The Ohio State University faculty and administrators clearly recognize the value of a program that delivers instruction on the full range of information resources and tools that are available to and widely used by students

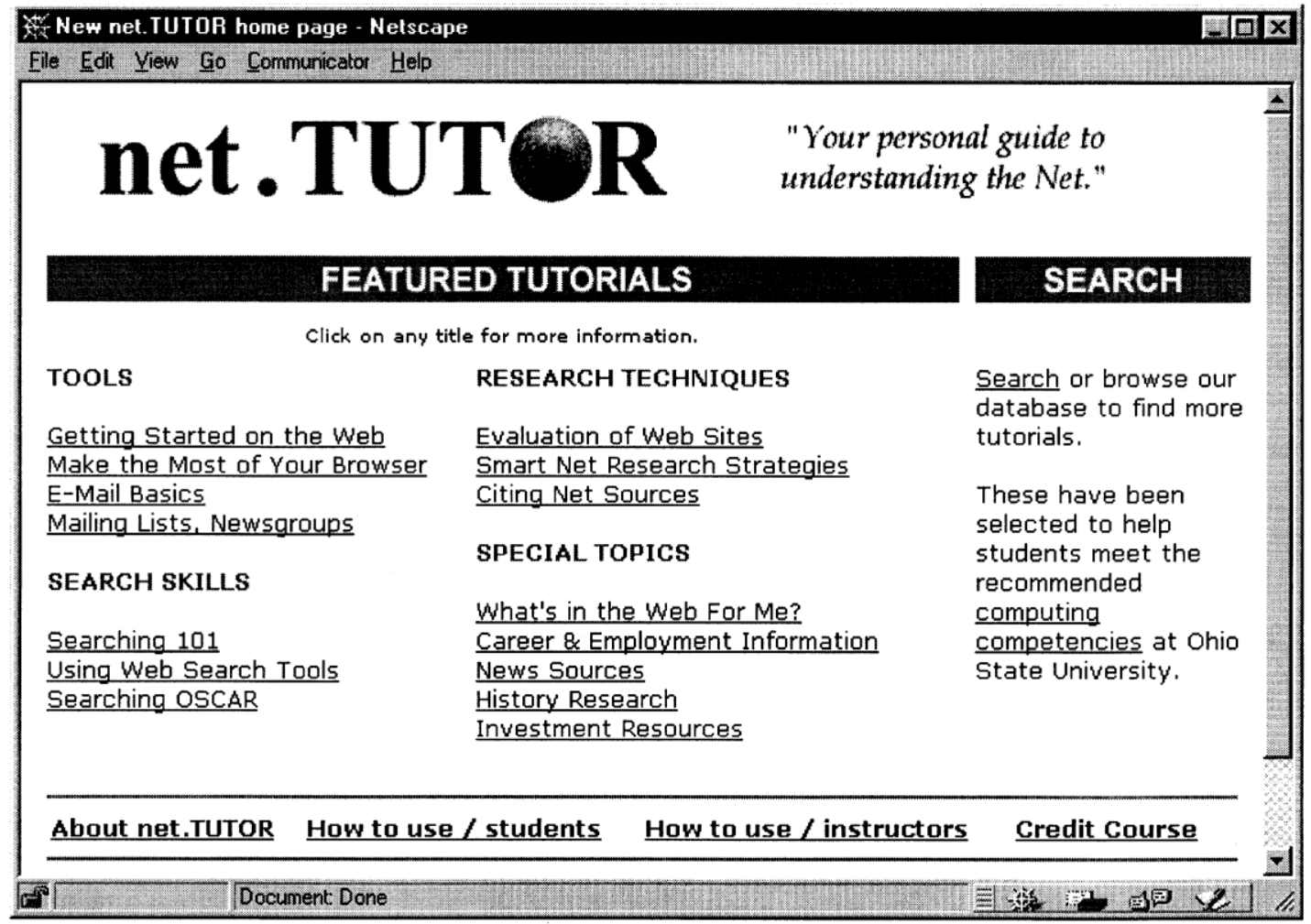

Fig. 4. net.TUTOR home page, version 2.0. 


\section{References}

Nielsen, J. (1997). Changes in web usability since 1994. Alertbox (December 1). Available at: http://www.useit.com/alertbox/9712a.html.

O'Hanlon, N. (1999). Web-based tutorials: does course use differ from general use? Journal of Interactive Learning Research, 10 (2), 217-228.

O'Hanlon, N., \& Roecker, F. (1999). How students use web-based tutorials and library assignments: case studies from the Ohio State University Libraries. In: Thompson H. A. (Ed.), Racing toward tomorrow: proceedings of the Ninth National Conference of the Association of College and Research Libraries, April 8-11 (pp. 335-341). Chicago: ACRL. 